

\section{Editor:}

Maison

Feri Tiona Pasaribu

Ahmad Syarkowi

Evtita

Novferma

Rosi Widia Asiani

Aulia Ul Millah

Martina Asti Rahayu

\section{Reviewer:}

Maison

Evita Anggereini

Haris Effendi

\section{Desain Sampul:}

Taufan Dyusanda Putra

ISBN: 978-602-50593-0-8

\section{Penerbit:}

Fakultas Keguruan dan Ilmu Pendidikan (FKIP)

bekerjasama dengan Fakultas Sains dan Teknologi (FST) Universitas Jambi

Redaksi:

Kampus Unja Mendalo

Jl. Raya Jambi - Ma. Bulian Km. 15, Mendalo Indah

Jambi

Telp./Fax: 0741 - 583453

ISBN $978-602-50593-0-8$

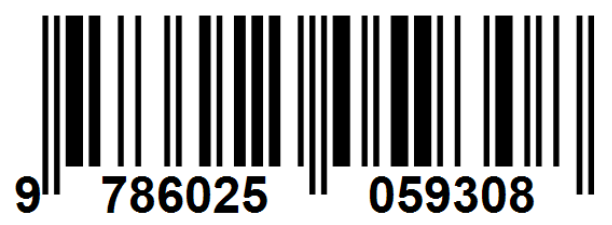




\section{KATA PENGANTAR}

Assalamualaikum Wr. Wb.

Alhamdulillah, segala puji bagi Allah SWT, Tuhan Yang Maha Esa, atas karunia yang telah dilimpahkan sehingga kegiatan Seminar dan Rapat Tahunan (SEMIRATA)-BKS PTN Bidang MIPA Wilayah Barat tahun 2017 dapat dilaksanakan secara baik.

Kegiatan SEMIRATA-BKS PTN Bidang MIPA Wilayah Barat tahun 2017 yang diamanahkan kepada Universitas Jambi sebagai penyelenggara dilaksanakan secara gabungan oleh Fakultas Sains dan Teknologi (FST) dan Fakultas Keguruan dan Ilmu Pendidikan (FKIP). Kegiatan telah dilaksanakan dengan sukses pada tanggal 12-14 Mei 2017 di Ratu Conference Hotel dan Swiss Bellin Hotel Jambi. Salah satu program utama adalah Seminar Nasional Sains dan Pendidikan MIPA dengan tema: "Peran Sains Teknologi dan Pendidikan MIPA dalam Menopang Sainspark, Teknopark serta Geopark berbasis Agroindustri dan Lingkungan”.

Sesi pleno seminar di Ratu Conference Center dipaparkan materi oleh dua pembicara utama yaitu akademisi Dr. Ir Yunus Kusumahbrata, M.Sc (Staf Ahli Kementerian ESDM) dan praktisi/birokrat Dr. H. Syahrial, M.P., (Bupati Tajung Jabung Barat Prov. Jambi). Materi yang disajikan berisi topik Pengembangan Geopark, Teknopark dan Sainspark di Indonesia. Selain daripada itu, sesi paralel telah dipresentasikan secara oral lebih dari 600 judul makalah hasil penelitian yang disampaikan dalam 40 ruang seminar secara paralel. Dalam kegiatan komunikasi ilmiah secara langsung ini juga telah dimanfaatkan untuk menjalin jejaring agar lebih bersinergi dalam pengembangan Sains dan Pendidikan MIPA ke masa mendatang.

Supaya komunikasi ilmiah yang baik ini dapat juga tersampaikan ke komunitas ilmiah lain yang tidak dapat hadir pada kegiatan seminar, panitia memfasilitasi untuk menerbitkan makalah dalam bentuk Prosiding. Panitia juga tetap memberi kesempatan kepada peserta yang akan menerbitkan makalahnya di jurnal ilmiah, sehingga tidak seluruh materi yang disampaikan pada seminar diterbitkan dalam prosiding ini. Dalam proses penerbitan prosiding ini, panitia telah banyak dibantu oleh Tim Reviewer dan Tim Editor yang dikoordinir oleh Drs. Maison, M.Si., Ph.D, yang telah dengan sangat intensif mencurahkan waktu, tenaga dan pikiran untuk melakukan proses plagiarism check, review, dan editing. Untuk itu, panitia menyampaikan terima kasih dan penghargaan. Namun, panitia juga menyampaikan permohonan ma'af karena dengan sangat banyaknya makalah yang akan diterbitkan dalam prosiding ini, waktu yang dibutuhkan dalam proses penerbitan prosiding ini cukup lama, dan penerbitan prosiding tidak dilakukan dalam satu buku tetapi dalam empat buku prosiding. Semoga penerbitan prosiding ini selain SEMIRATA-BKS PTN Bidang MIPA Wilayah Barat tahun 2017 bermanfaat bagi para pemakalah dan penulis, juga dapat bermanfaat dalam pengembangan Sains dan Pendidikan MIPA di Indonesia.

Ucapan terima kasih disampaikan kepada Rektor Universitas Jambi, Dekan FST dan FKIP Universitas Jambi, Ketua Forum Rektor BKS wilayah Barat, Ketua BKS-MIPA Wilayah Barat, panitia dan semua pihak yang ikut menyukseskan acara semirata.

Jambi, 2 Oktober 2017

Ketua Panitia

Dr. Kamid, M.Si 


\section{DAFTAR ISI}

BUKU 1 (MATEMATIKA)

IMPLEMENTASI ALGORITMA GENETIKA SISTEM PENJADWALAN REGISTRASI DINAMIS

Suyanto, Syahriol Sitorus dan Usman Ridwan Syah

APLIKASI SISTEM ANTRIAN BERBASIS ANDROID

Joko Risanto

MODEL OPTIMASI LAHAN PARKIR GRAPARI BANDA ACEH DENGAN

MENGGUNAKAN SATUAN RUANG PARKIR

Phounna Mandira Chalandri, Intan Syahrini, Taufiq Iskandar, Marwan Ramli

PENENTUAN LINTASAN TERPENDEK PADA SUATU GRAP BERBOBOT DENGAN

MENGGUNAKAN PROGRAM DINAMIK

Eldawati, Said Munzir, Marwan Ramli

PREDIKSI HARGA DAGING SAPI DI PEKANBARU DENGAN METODE PEMULUSAN EKSPONENSIAL TRIPEL WINTER

Evi Febriantikasari, Rado Yendra, Arisman Adnan, Rahmadeni

PREMI TAHUNAN ASURANSI JIWA BERJANGKA DENGAN ASUMSI SERAGAM

UNTUK STATUS GABUNGAN

Desta Wahyuni, Rado Yendra, Arisman Adnan, Nilwan Andiraja

OPERATOR LINEAR PADA RUANG BARISAN TERBATAS $l_{2}$

Muslim Ansori, Suharsono,S

APLIKASI KONTROL OPTIMAL PADA POLAR ROBOT UNTUK OBJEKTIF GANDA:

MEMINIMUMKAN BESAR TORSI DAN PENCAPAIAN POSISI TARGET DENGAN

WAKTU MINIMUM

Said Munzir, Marwan, Taufiq Iskandar dan Reza Wafdan

PENGGUNAAN METODE FIS MAMDANI DALAM MEMPERKIRAKAN TERJADINYA GELOMBANG TSUNAMI AKIBAT GEMPA BUMI

73

Hizir Sofyan, Erni Lusiani , Asep Rusyana , Marzuki

OPTIMALISASI PORTOFOLIO DENGAN MENGGUNAKAN SEPARABLE

PROGRAMMING

Elly Rosmaini dan Nurhalimah Pane

MODEL MATEMATIKA PENYEBARAN PENYAKIT MALARIA

Syarifah Meurah Yuni, Mahmudi

ANALISIS PERSONAL FINANCIAL LITERACY MAHASISWA DALAM

MERAMALKAN JUMLAH PENGELUARAN MENGGUNAKAN METODE

EXPONENTIAL SMOOTHING DAN P-SPLINE FILTER SMOOTHING (Studi Kasus :

Universitas Syiah Kuala, Banda Aceh)

Putri Atikah, Maisarah Defadz, Siti Husna F., Miftahuddin 
SIKAP MAHASISWA TERHADAP MATAKULIAH FISIKA DASAR DI PROGRAM

1156 STUDI PENDIDIKAN FISIKA FAKULTAS KEGURUAN DAN ILMU PENDIDIKAN UNIVERSITAS JAMBI

Titi Nurjanah, Astalini , Wawan Kurniawan

EFFECTIVENESS OF PHYSICS LEARNING BASED ON MULTI REPRESENTATION

1166 TO GAIN THE STUDENTS PHYSICS EDUCATION REPRESENTATION ABILITY Yennita EFEKTIVITAS LKPD BERORIENTASI KOMPLEKSITAS KONTEN DAN PROSES KOGNITIF UNTUK PEMBELAJARAN FISIKA SMA/MA

Harman Amir, Amali Putra, Vera Yunita

ANALISIS POLA PIKIR DAN PERILAKU LINGKUNGAN MAHASISWA PROGRAM STUDI PENDIDIKAN FISIKA FKIP UNRI TERHADAP LINGKUNGAN HIDUP DI KAMPUS FKIP UNRI

Muhammad Syafi'I, M. Nor

ANALISIS PERSEPSI MAHASISWA PENDIDIKAN FISIKA TERKAIT PENTINGNYA PEMBELAJARAN FISIKA BERMAKNA YANG MENERAPKAN UNSUR KEARIFAN LOKAL SUMATERA BARAT

Renol Afrizon, Hidayati, Rio Anshari

UPAYA PENINGKATAN KETERAMPILAN KOMUNIKASI DAN BERPIKIR KRITIS

1223

MELALUI MODEL PROBLEM BASED LEARNING MAHASISWA PENDIDIKAN

BIOLOGI PADA MATA KULIAH FISIKA DASAR 1

Muhammad Nor, Zuhdi Maaruf, M. Syafi'i

PENINGKATAN KETERAMPILAN LITERASI INFORMASI, KOMUNIKASI, DAN HASIL BELAJAR MELALUI PENDEKATAN SAINTIFIK. PERKULIAHAN

SEJARAH FISIKA MAHASISWA FKIP UNIVERSITAS RIAU

Zuhdi M, Muh Nor

DISAIN LABORATORUM VIRTUAL MELALUI ICT PADA MATA PELAJARAN FISIKA SMA

Masril, Hidayati, Yenni Darvina

KARAKTERISTIK BAHAN AJAR FISIKA BERORIENTASI PADA KOMPLEKSITAS KONTEN DAN PROSES KOGNITIF UNTUK PEMBELAJARAN FISIKA SMA

Amali Putra, Adree Octova

PERAN MULTIMEDIA VIRTUAL LERNING TERHADAP PENINGKATAN KOMPETENSI PSIKOMOTOR FISIKA SISWA SMA PEKANBARU

Muhammad Nasir

IMPLEMENTATION DISCOVERY LEARNING MODLE IN PHYSICS CLASSROOM SMPN 2 KOTA BENGKULU

Indra Sakti, Chendya TW

PENGARUH PEMBELAJARAN GENERATIF BERBASIS STRATEGI KONFLIK 


\title{
ANALISIS PERSEPSI MAHASISWA PENDIDIKAN FISIKA TERKAIT PENTINGNYA PEMBELAJARAN FISIKA BERMAKNA YANG MENERAPKAN UNSUR KEARIFAN LOKAL SUMATERA BARAT
}

\author{
Renol Afrizon, Hidayati, Rio Anshari \\ ${ }^{1}$ Matematika dan Ilmu Pengetahuan Alam, Universitas Negeri Padang \\ email: renol.afrizon@yahoo.com ${ }^{1)}$
}

\begin{abstract}
ABSTRAK
Mahasiswa jarang memulai permasalahan kehidupan sehari-hari di awal penyajian materi fisika. Tujuan penelitian adalah untuk mendeskripsikan persepsi mahasiswa terkait pentingnya pembelajaran fisika bermakna. Penelitian ini menggunakan metode survei. Penelitian ini berfokus pada tahap deskripsi gejala. Pengumpulan data dilakukan dengan menggunakan angket. Teknik analisis yang digunakan untuk mengolah data adalah teknik persentase. Subjek penelitian adalah mahasiswa yang mengambil matakuliah fisika SMA/MA dan SMK Kelas XI pada semester Januari-Juni 2017. Hasil penelitian yang diperoleh adalah berikut ini. 1) 63,86\% mahasiswa hanya menguasai materi dengan cara hafalan sehingga sering mengalami miskonsepsi. 2) $55 \%$ lebih mahasiswa dapat memahami model dan pendekatan pembelajaran yang dianjurkan kurikulum 2013 tetapi sulit untuk menerapkannya. 3) 50\% lebih mahasiswa tidak mengalami kesulitan menemukan referensi pembelajaran terkait permasalahan di alam dan di sekitar mahasiswa. 4) lebih dari 50\% mahasiswa belum mengenal dan belum menjadikan kearifan lokal sebagai sumber belajar. 5) lebih dari 87\% mahasiswa berpendapat bahwa menggunakan kearifan lokal di awal pembelajaran fisika dapat menjadikan pembelajaran lebih bermakna. Kesimpulan penelitian adalah gambaran pemahaman mahasiswa mengenai pentingnya pembelajaran bermakna yang memuat unsur kearifan lokal sehingga dapat dijadikan dasar untuk mengeksplorasi konsep-konsep fisika pada kearifan lokal yang ada di Sumatera Barat.
\end{abstract}

Kata Kunci: pembelajaran fisika, pembelajaran bermakna, kearifan lokal, Sumatera Barat

\section{PENDAHULUAN}

Mahasiswa pendidikan fisika merupakan calon guru fisika yang perlu dibekali dengan berbagai mata kuliah yang dapat menunjang penelaahan materi fisika sekolah menengah. 
Program studi pendidikan fisika telah menyediakan beberapa matakuliah, salah satunya adalah fisika SMA/MA dan SMK Kelas XI. Kemendikbud (2016: 3) menjelaskan beberapa tujuan pembelajaran fisika di SMA/MA yang harus dimiliki peserta didik adalah: 1) memahami fenomena alam di sekitarnya, berdasarkan hasil pembelajaran sains melalui bidang-bidang fisika; 2) menyelesaikan masalah yang dihadapi dalam kehidupannya, terutama memilih di antara cara-cara yang telah dikenal manusia berdasarkan pertimbangan ilmiah; 3) mengenali dan menghargai peran fisika dalam memecahkan permasalahan umat manusia; dan 4) memahami dampak dari perkembangan fisika terhadap perkembangan teknologi dan kehidupan manusia di masa lalu, maupun potensi dampaknya di masa depan bagi dirinya, orang lain, dan lingkungannya.

Suparno (2007: 2) mengemukakan unsur yang terpenting dalam pembelajaran fisika yang baik adalah: (1) peserta didik yang belajar, (2) guru yang mengajar, (3) bahan pelajaran, dan (4) hubungan antara guru dan peserta didik. Bagian penting dalam pembelajaran fisika adalah bagaimana cara menjadikan peserta didik aktif belajar fisika. Semua usaha guru harus diarahkan untuk memfasilitasi dan memotivasi agar peserta didik berminat mempelajari fisika itu sendiri. Komunikasi guru dan peserta didik juga penting dijalin sehingga dapat saling mendukung. Pihak guru diharapkan menguasai bahan yang mau diajarkan, melaksanakan pembelajaran sesuai dengan karakteristik dan perkembangan peserta didik, dan dapat menyusun bahan sehingga mudah diterima secara baik oleh peserta didik.

Guru fisika harus berusaha keras menguasai bahan yang akan diajarkan sehingga tidak menimbulkan miskonsepsi pada diri peserta didik. Guru fisika harus terus mengembangkan diri dengan mempelajari konsep fisika secara mendalam. Pengembangan bahan ajar oleh guru fisika SMA harus lebih tinggi atau setingkat universitas sehingga dapat memberikan wawasan lebih luas kepada peserta didik. Sumber belajar fisika yang dapat digunakan untuk menambah pengetahuan dalam mengembangkan bahan ajar seperti internet, buku-buku fisika dasar, seminar, lokakarya, bertanya pada tenaga ahli, dan alam sekitar. Pembelajaran melibatkan alam sekitar sebagai sumber belajar akan mampu menunjang penerapan pembelajaran fisika sesuai tuntutan kurikulum 2013.

Pemberlakuan kurikulum 2013 juga menuntut seorang guru agar menggunakan pendekatan saintifik di dalam pembelajarannya. Model pembelajaran yang dianjurkan di dalam pembelajaran sesuai kurikulum 2013 adalah model discovery learning, inquiry learning, problem based learning, project based learning (Permendikbud nomor 22 tahun 2016). Model inquiry learning memulai sintaknya dengan cara observasi/mengamati sebuah fenomena. Model discovery learning memulainya dengan tahap stimulation (memberi stimulus); bacaan, atau gambar, atau situasi, sesuai dengan materi pembelajaran/topik/tema. Model problem based learning harus mengorientasikan pada masalah di awal kegiatan pembelajarannya. Model project based learning menganjurkan agar mengamati lebih dalam terhadap pertanyaan yang muncul dari fenomena yang ada. Jadi, semua model pembelajaran fisika yang diajurkan oleh kurikulum 2013 memulai pembelajarannya dengan fenomena/masalah yang ada di alam dan di sekitar peserta didik.

Penulis telah melakukan wawancara dengan dosen fisika FMIPA UNP yang mengampu matakuliah pembelajaran mikro. Dari hasil wawancara penulis diperoleh kenyataan bahwa mahasiswa pendidikan fisika kesulitan dalam mengaitkan konsep fisika dengan permasalahan yang ada dalam kehidupan sehari-hari. Selain itu, penulis juga melakukan analisis terhadap 
tugas yang dikerjakan oleh mahasiswa pendidikan fisika yang mengambil matakuliah fisika SMA/MA dan SMK Kelas XI. Tugas yang dikerjakan oleh mahasiswa berupa mind map terkait kajian materi fisika yang dikuasai oleh mahasiswa. Hasil analisis terhadap mind map kajian materi diperoleh beberapa temuan: 1) 12,50\% mahasiswa hanya menyajikan sub judul materi, 2) 51,19\% mahasiswa hanya menyajikan konsep berupa rumus-rumus fisika, 3) 27,38\% mahasiswa menyajikan konsep-konsep fisika berupa rumus fisika yang dilengkapi ilustrasi gambar, dan 4) hanya 8,93\% mahasiswa yang menyajikan konsep-konsep fisika dilengkapi ilustrasi gambar dan permasalahan dalam kehidupan sehari-hari.

Jarangnya mahasiswa yang mampu mengaitkan konsep fisika dengan peristiwa kehidupan sehari-hari menimbulkan kesulitan tersendiri bagi mahasiswa dalam merancang permasalahan di awal penyajian materi fisika SMA. Dengan demikian, perlu dikembangkan sumber belajar yang ada dalam kehidupan sehari-hari. Kearifan lokal yang ada pada suatu daerah merupakan salah satu sumber belajar yang ada di alam yang dan dekat dengan peserta didik. Kearifan lokal sesungguhnya mengandung banyak sekali keteladanan dan kebijaksanaan hidup. Pentingnya mengajarkan kearifan lokal dalam pembelajaran merupakan bagian upaya meningkatkan ketahanan nasional. Budaya Indonesia khususnya Sumatera Barat merupakan sumber kearifan lokal yang mampu bertahan karena semuanya merupakan kenyataan hidup yang tidak dapat dihindari. Oleh karena itu, perlu disediakan bahan kajian konsep fisika yang memuat unsur kearifan lokal Sumatera Barat.

Sebelum mengkaji konsep fisika yang memuat unsur kearifan lokal Sumatera Barat, maka perlu dilakukan survei deskriptif. Survei ini diberikan kepada mahasiswa pendidikan fisika FMIPA UNP yang sedang mengambil matakuliah fisika SMA/MA dan SMK Kelas XI dan pembelajaran mikro. Hal ini karena mahasiswa yang bersangkutan telah berusaha menerapkan kompetensi guru fisika di kelas. Survei deskriptif bertujuan untuk melihat sejauh mana penguasaan materi fisika mahasiswa, kemampuan mahasiswa menyajikan materi, persepsi yang dimiliki mahasiswa terkait pentingnya pembelajaran fisika bermakna.

\section{KAJIAN LITERATUR}

Kemendikbud (2016: 3) mengemukakan bahwa pengembangan kurikulum fisika SMA/MA dilakukan dalam rangka mencapai dimensi kompetensi pengetahuan, kerja ilmiah, serta sikap ilmiah sebagai perilaku sehari-hari dalam berinteraksi dengan masyarakat, lingkungan dan pemanfaatan teknologi. Penyajian pembelajaran fisika relevan dengan kerangka pengembangan Ilmu Pengetahuan Alam (IPA). Kearifan lokal dapat menunjang unsur sains dalam kehidupan sehari-hari dan lingkungan pada kerangka ini. Hal ini tersaji pada Gambar 1.

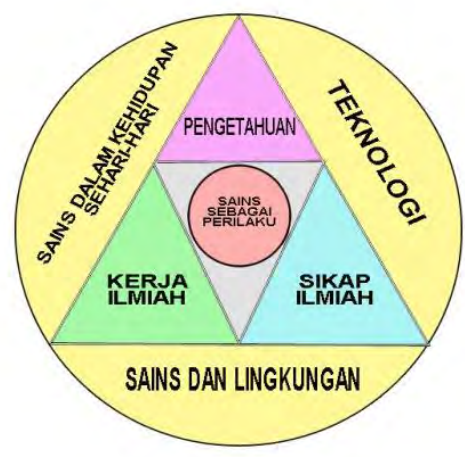


Gambar 1. Kerangka Pengembangan IPA

(Sumber: Kemendikbud (2016: 3))

Doddy Soedigdo, Ave Harysakti, dan Tari Budayanti Usop (2014: 38-40) mengemukakan wujud kearifan lokal dapat dikategorikan ke dalam dua aspek, yaitu kearifan lokal yang berwujud nyata (tangible) dan yang tidak berwujud (intangible). Kearifan lokal tangible (berwujud fisik) meliputi: 1) kearifan lokal yang tertuang dalam bentuk catatan tertulis seperti primbon dan praksi (budaya tulis di atas lembaran daun lontar), 2) karya-karya arsitektur/bangunan tradisional misalnya Rumah Gadang, dan 3) benda cagar budaya, karya seni/kerajinan tangan tradisional misalnya keris dan batik. Sedangkan, kearifan lokal intangible (tidak berwujud) meliputi petuah-petuah yang disampaikan secara verbal dan turun-temurun dapat berupa nyanyian, kidung yang mengandung ajaran-ajaran tradisional.

Pemaknaan terhadap kearifan lokal dalam dunia pendidikan masih sangat kurang. Istilah yang sering digunakan dalam struktur kurikulum adalah muatan lokal. Pemaknaannya terhadap muatan lokal masih bersifat formal karena muatan lokal kurang mengeksporasi kearifan lokal. Muatan lokal hanya sebatas bahasa dan tari daerah yang diajarkan kepada peserta didik. Dunia pendidikan memiliki tantangan yang sangat kompleks dewasa ini. Hal ini terlihat dari mulai memudar dan ditinggalkannya nilai-nilai lokal seiring dengan pengaruh kemajuan global di bidang sains dan teknologi. Oleh karena itu, eksplorasi terhadap kekayaan luhur budaya bangsa sangat perlu untuk dilakukan.

Salah satu cara yang dapat dilakukan adalah mengkaji konsep-konsep fisis yang terkandung pada kearifan lokal yang sudah ada. Hal ini perlu dikaji secara mendalam sehingga dapat dijadikan referensi oleh mahasiswa pendidikan fisika dalam merancang pembelajaran yang menggunakan pendekatan saintifik. Pengetahuan baru yang menerapkan unsur kearifan lokal dapat memberi manfaat pada diri peserta didik. Hal ini akan membuat pembelajaran fisika yang dirancang oleh mahasiswa calon guru akan menjadi lebih bermakna. Ausabel dan Novak dalam Dahar (2011: 98) mengemukakan kebaikan belajar bermakna, yaitu: (a) informasi yang dipelajari secara bermakna lebih lama dapat diingat daripada belajar hafalan, (b) mempermudah proses belajar berikutnya untuk hal-hal yang mirip diakibatkan asimilasi pengetahuan baru.

\section{METODE PENELITIAN}

Jenis penelitian yang dilakukan adalah penelitian survei. Survei dapat dilakukan untuk berbagai penelitian yang bertujuan deskriptif, eksplanatif, dan eksploratif (Morrison, 2015: 165). Penelitian yang telah dilaksanakan berupa survei yang bertujuan deskriptif. Hasil survei ini memberikan gambaran karakteristik mahasiswa pendidikan fisika terkait penguasaan materi fisika, penyajian materi fisika, dan persepsi pentingnya pembelajaran fisika bermakna. Gambaran ini dapat dijadikan dasar untuk mengeksplorasi penerapan konsep-konsep fisika pada unsur kearifan lokal budaya Sumatera Barat. 
Rincian langkah kegiatan yang telah dilaksanakan pada tahap ini adalah melaksanakan survei deskriptif kepada 83 mahasiswa pendidikan fisika. Penelitian ini sedang berlangsung pada semester Januari-Juni 2017 di Jurusan Fisika FMIPA UNP. Subjek dari penelitian ini adalah mahasiswa yang mengambil perkuliahan fisika SMA/MA dan SMK Kelas XI. Pengumpulan data dilakukan dengan angket. Teknik analisis yang digunakan untuk mengolah data adalah teknik persentase dan disajikan pada grafik.

\section{HASIL DAN PEMBAHASAN}

\section{a. Hasil Penelitian}

Kondisi perkuliahan Fisika SMA/MA dan SMK Kelas XI dapat dideskripsikan dalam dua kategori yaitu deskripsi penguasaan dan penyajian materi fisika mahasiswa pendidikan fisika UNP saat ini dan deskripsi persepsi mahasiswa terkait dampak pembelajaran yang memuat permasalahan yang ada di alam dan di sekitar peserta didik. Kedua deskripsi dijelaskan secara detil berikut ini.

1) Deskripsi Penguasaan dan Penyajian Materi Fisika oleh Mahasiswa Pendidikan Fisika UNP

Hasil analisis kondisi deskripsi penguasaan dan penyajian materi fisika mahasiswa pendidikan fisika UNP dapat dijabarkan dalam beberapa hal berikut ini.

a) Deskripsi Penguasaan Materi Fisika Mahasiswa

Penguasaan materi fisika mahasiswa dapat diketahui dengan menyebarkan angket pada perkuliahan Fisika SMA/MA dan SMK Kelas XI. Hasil analisis deskripsi penguasaan materi fisika mahasiswa tersaji seperti pada Gambar 2.

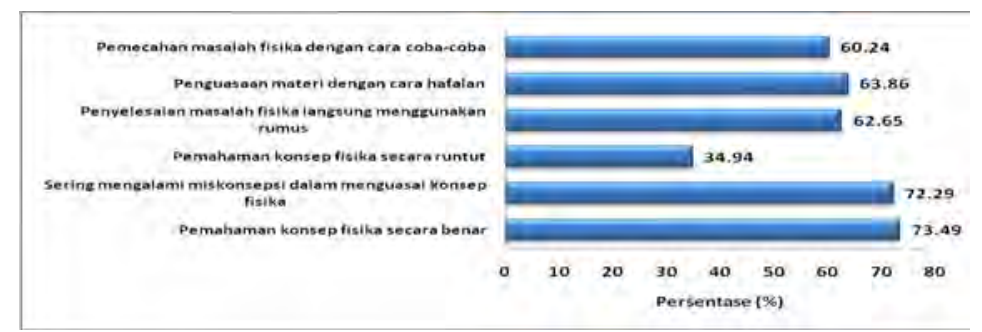

Gambar 2. Hasil Analisis Penguasaan Materi Fisika Mahasiswa Pendidikan Fisika UNP

Berdasarkan Gambar 2, pemahaman konsep fisika mahasiswa secara benar berada pada persentase tertinggi, yakni 73,49\%. Meskipun demikian, 72,29\% mahasiswa masih sering mengalami miskonsepsi dalam menguasai konsep fisika. Dari segi keruntutan penguasaan materi fisika, terlihat hanya 34,94\% mahasiswa yang mampu menguasai secara runtut sehingga mengakibatkan lebih $60 \%$ mahasiswa menyelesaikan permasalahan fisika secara coba-coba. Disamping itu, penguasaan materi fisika oleh mahasiswa masih mendominasi dengan cara hafalan. Hal ini berdampak signifikan (62,65\%) pada pada penyelesaian masalah fisika yang langsung menggunakan rumus tanpa memahami maksud permasalahan tersebut secara mendetil dan mendalam.

\section{b) Deskripsi Penyajian Materi dalam Perkuliahan Fisika SMA/MA dan SMK Kelas XI}

Hasil penyebaran angket memberikan gambaran bagaimana cara mahasiswa menyajikan materi dalam perkuliahan fisika SMA/MA dan SMK Kelas XI. Deskripsi ini terlihat pada Gambar 3. 


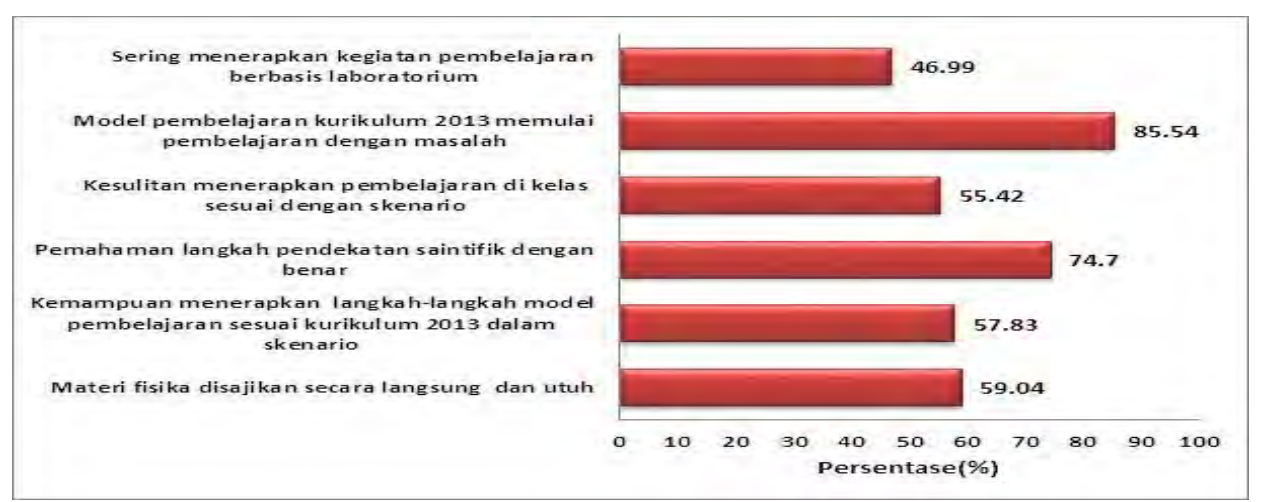

Gambar 3. Hasil Analisis Penyajian Materi Fisika di Pembelajaran di Kelas

Gambar 3 memperlihatkan kemampuan mahasiswa dalam menyajikan materi fisika di dalam kelas. 59,04\% mahasiswa langsung menyajikan materi fisika secara utuh. Dari segi pemahaman mahasiswa terkait kurikulum 2013, terlihat 74,70\% mahasiswa memahami langkah-langkahnya pendekatan saintifik dengan benar, $85 \%$ lebih mahasiswa dapat memahami model pembelajaran yang dianjurkan kurikulum 2013. 55\% mahasiswa mampu merancangnya pada skenario tetapi sulit untuk menerapkannya di kelas. Selain itu, $47 \%$ mahasiswa yang hanya menerapkan kegiatan pembelajaran berbasis laboratorium.

\section{c) Deskripsi Pemanfaatan Sumber Belajar dalam Penguasaan dan Penyajian Materi Fisika}

Sumber belajar dimanfaatkan sebagai referensi dalam menguasai dan menyajikan materi fisika. Pemanfaatan sumber belajar oleh mahasiswa dilihat melalui angket. Hasil analisisnya seperti pada Gambar 4.

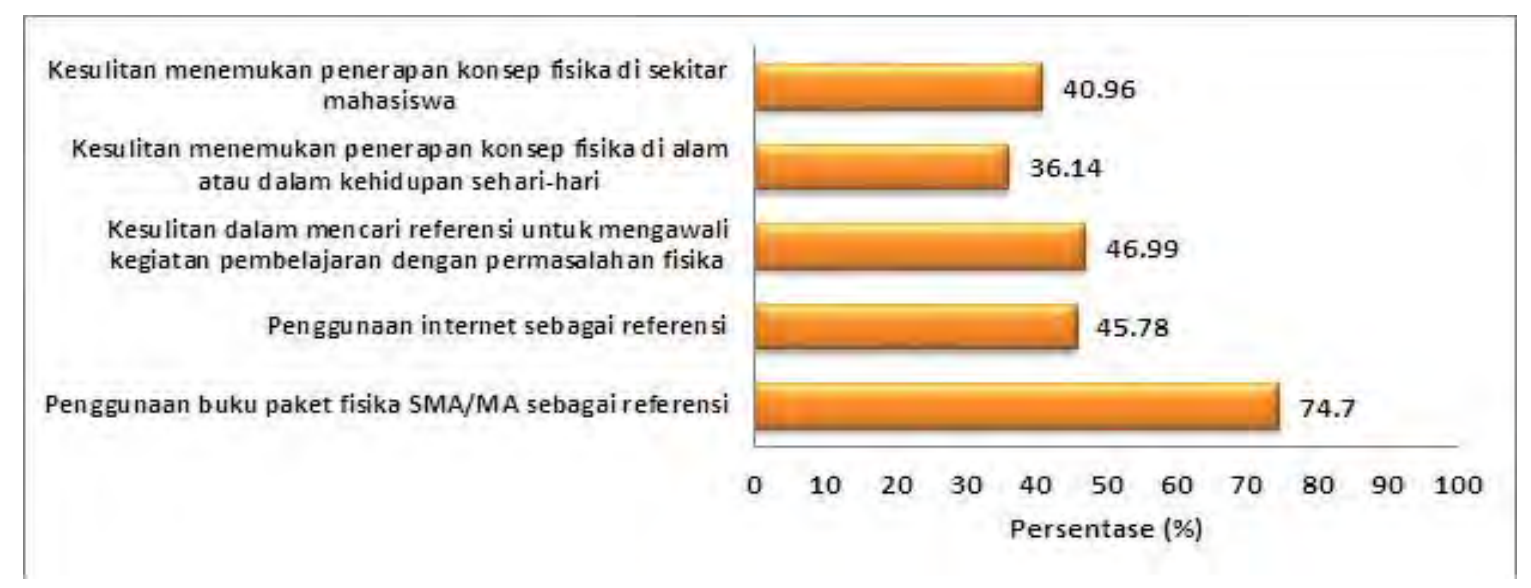

Gambar 4. Hasil Analisis Pemanfaatan Sumber Belajar

Gambar 4 memperlihatkan bahwa mahasiswa lebih banyak menggunakan buku paket fisika SMA/MA daripada internet sebagai referensi dalam penguasaan dan penyajian materi fisika. 46,99\% mahasiswa kesulitan dalam mencari referensi permasalahan fisika dalam mengawali kegiatan pembelajaran. Sedangkan, jumlah mahasiswa yang kesulitan menemukan penerapan konsep fisika dalam kehidupan sehari-hari dan dekat dengan mahasiswa dibawah $45 \%$. 


\section{d) Deskripsi Pemanfaatan Kearifan Lokal Sebagai Sumber Belajar}

Salah satu sumber belajar yang dekat dengan mahasiswa dan ada dalam kehidupan seharihari adalah kearifan lokal. Hasil analisis pemanfaatan kearifan lokal sebagai sumber belajar terdapat pada Gambar 5.

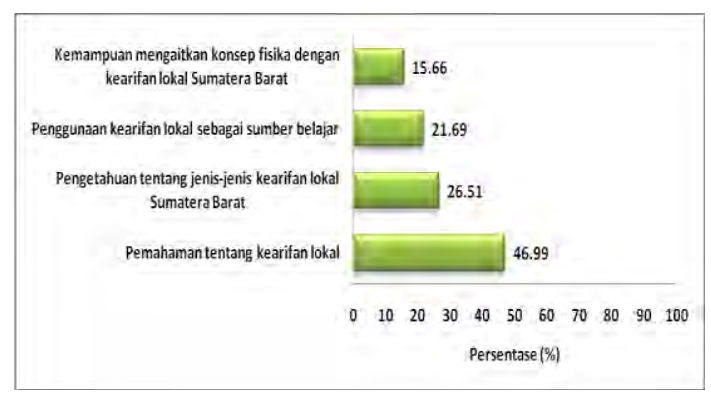

Gambar 5. Hasil Analisis Pemanfaatan Kearifan Lokal sebagai Sumber Belajar

Pemanfaatan kearifan lokal sebagai sumber belajar oleh mahasiswa masih rendah. Hal ini dibuktikan hanya 46,99\% mahasiswa yang paham tentang kearifan lokal; 26,51\% mahasiswa yang mengetahui jenis-jenis kearifan lokal Sumatera Barat; dan hanya 21,69\% mahasiswa yang menggunakannya sebagai sumber belajar. Rendahnya pemanfaatan kearifan lokal dalam kegiatan pembelajaran fisika berdampak pada jumlah mahasiswa yang mampu mengaitkan konsep fisika dengan kearifan lokal Sumatera Barat juga rendah yaitu hanya $15,66 \%$.

2) Persepsi mahasiswa terkait dampak pembelajaran yang memuat permasalahan yang ada di alam dan di sekitar peserta didik

Mahasiswa pendidikan fisika diminta pendapatnya terkait dampak jika mahasiswa tersebut menerapkan pembelajaran fisika yang memuat permasalahan di alam dan di sekitar peserta didik. Hasil analisis persepsi mahasiswa terlihat pada Gambar 6 .

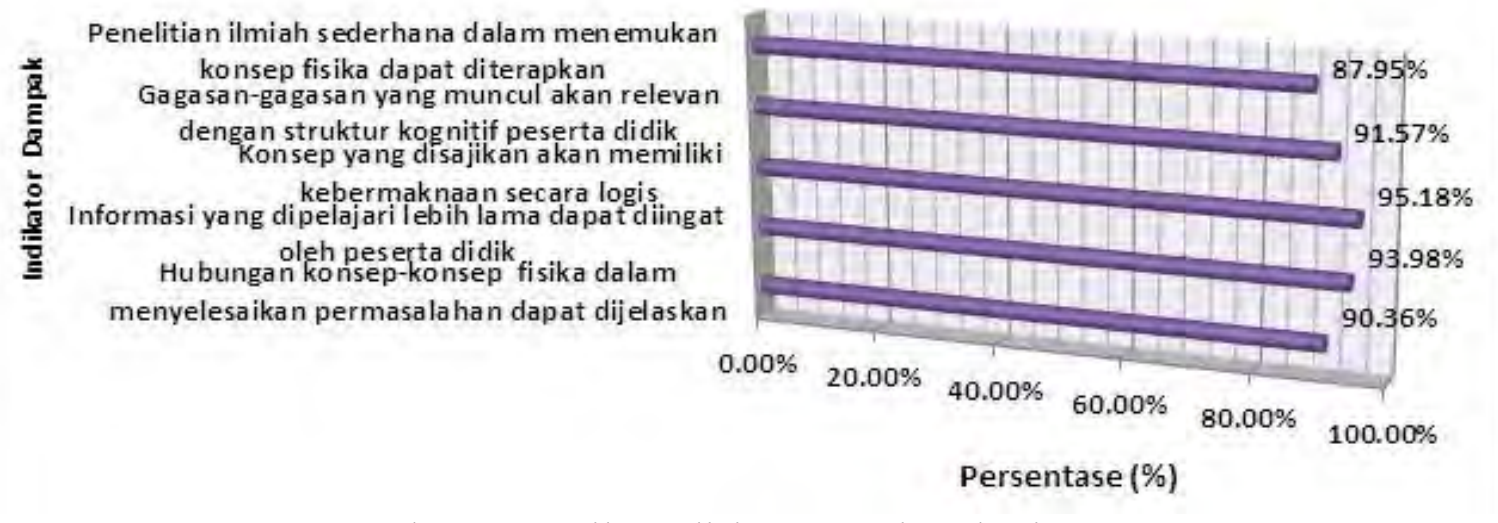

Gambar 6. Hasil Analisis Persepsi Mahasiswa

Berdasarkan Gambar 6, terlihat bahwa lebih dari 87\% mahasiswa memiliki persepsi jika pembelajaran fisika memuat permasalahan yang ada dalam kehidupan sehari-hari dan dekat dengan peserta didik akan menimbulkan dampak positif. Dampak positif yang dihasilkan dalam pembelajaran, diantaranya: 1) hubungan konsep-konsep fisika dalam menyelesaikan permasalahan dapat dijelaskan, 2) informasi yang dipelajari lebih lama dapat diingat oleh peserta didik, 3) konsep yang disajikan akan memiliki kebermaknaan secara logis, 4) gagasan-gagasan yang muncul akan relevan dengan struktur kognitif peserta didik, 5) 
penelitian ilmiah sederhana dalam menemukan konsep fisika dapat diterapkan. Hal ini menunjukkan bahwa pembelajaran fisika yang akan terlaksana akan bermakna bagi calon guru dan peserta didik nantinya.

\section{b. Pembahasan}

Hasil penelitian menunjukkan bahwa: a). mahasiswa hanya menguasai materi dengan cara hafalan sehingga sering mengalami miskonsepsi. b) mahasiswa dapat memahami model dan pendekatan pembelajaran yang dianjurkan kurikulum 2013 tetapi sulit untuk menerapkannya. c) mahasiswa tidak mengalami kesulitan menemukan referensi pembelajaran terkait permasalahan di alam dan di sekitar mahasiswa. d) lebih separuh mahasiswa belum mengenal dan belum menjadikan kearifan lokal sebagai sumber belajar. Jadi, perkuliahan Fisika SMA/MA dan SMK Kelas XI saat ini belum sepenuhnya bermakna bagi mahasiswa.

Pembelajaran akan lebih bermakna apabila pembelajaran yang dirancang berawal dari permasalahan kehidupan sehari-hari dan dekat dengan peserta didik sehingga memotivasi peserta didik untuk menyukai pembelajaran yang berlangsung. Salah satu sumber yang dapat dijadikan referensi adalah bahan kajian konsep fisika terkait kearifan lokal misalnya, mengkaji konsep fisika pada Rumah Gadang. Nurma Ali Ridwan dalam Wikantiyoso, Respati dan Pindo Tutuko (2009: 7) mengemukakan bahwa kearifan lokal (local wisdom) dapat dipahami sebagai usaha manusia dengan menggunakan akal budinya (kognisi) untuk bertindak dan bersikap terhadap sesuatu, objek, atau peristiwa yang terjadi dalam ruang tertentu. Dengan demikian, diharapkan mahasiswa lebih memiliki minat, motivasi dan wawasan dalam mengaitkan permasalahan fisika kehidupan sehari-hari dengan pembelajaran sesuai dengan anjuran kurikulum 2013.

Hasil persepsi mahasiswa pendidikan fisika menunjukkan bahwa pembelajaran bermuatan kearifan lokal memberi dampak terhadap pembelajaran fisika. Pembelajaran fisika menjadi lebih bermakna bagi mahasiswa sebagai calon guru dan peserta didik nantinya. Hal ini dikarenakan proses pembelajaran fisika bermuatan kearifan lokal dapat mengaitkan informasi yang baru dengan informasi yang telah ada pada diri peserta didik. Selain itu, pembelajaran fisika juga menghasilkan sesuatu yang berguna dan lebih bermanfaat bagi peserta didik ketika mereka telah dewasa seperti desain rumah tahan gempa yang telah diwariskan oleh nenek moyang kita seperti rumah gadang. Hal ini sejalan dengan teori Ausabel bahwa belajar bermakna merupakan suatu proses dikaitkannya informasi baru pada konsep-konsep relevan yang terdapat dalam struktur kognitif seseorang (Dahar, 2011: 95).

\section{KESIMPULAN}

Berdasarkan hasil analisis kondisi perkuliahan Fisika SMA/MA dan SMK Kelas XI yang telah berlangsung, diperoleh beberapa kesimpulan: a). Pertama, 63,86\% mahasiswa hanya menguasai materi dengan cara hafalan sehingga sering mengalami miskonsepsi. b) Kedua, 55 $\%$ lebih mahasiswa dapat memahami model dan pendekatan pembelajaran yang dianjurkan kurikulum 2013 tetapi sulit untuk menerapkannya. c) Ketiga, 50\% lebih mahasiswa tidak mengalami kesulitan menemukan referensi pembelajaran terkait permasalahan di alam dan di sekitar mahasiswa. d) Keempat, lebih dari 50\% mahasiswa belum mengenal dan belum menjadikan kearifan lokal sebagai sumber belajar. e) Kelima, lebih dari 87\% mahasiswa 
berpendapat bahwa menggunakan kearifan lokal sebagai permasalahan di awal pembelajaran fisika dapat membuat pembelajaran menjadi lebih bermakna. Hal ini dapat dijadikan dasar perlunya mengeksplorasi konsep-konsep fisika pada kearifan lokal yang ada di Sumatera Barat.

\section{REFERENSI}

Dahar, R.W. 2011. Teori-Teori Belajar dan Pembelajaran. Bandung: Erlangga.

Doddy Soedigdo, Ave Harysakti, dan Tari Budayanti Usop. 2014. Elemen-Elemen Pendorong Kearifan Lokal pada Arsitektur Nusantara. Jurnal Perspektif Arsitektur, Vol. 9 No.1 hal: 37-47, ISSN: $1907-8536$

Kemendikbud. 2016. Silabus Mata Pelajaran Fisika Sekolah Menengah Atas/ Madrasah Aliyah (SMA/MA). Jakarta: Kementerian Pendidikan dan Kebudayaan.

Morrison. 2015. Metode Penelitian Survei. Jakarta: Prenadamedia Group.

Permendikbud nomor 22 Tahun 2016 tentang Standar Proses Pendidikan Dasar dan Menengah. Jakarta: Kementerian Pendidikan dan Kebudayaan.

Suparno, P. 2007. Metodologi Pembelajaran Fisika Konstruktivistik \& Menyenangkan. Yogyakarta: Universitas Sanata Dharma

Wikantiyoso, Respati dan Pindo Tutuko. 2009. Kearifan Lokal dalam Perencanaan dan Perancangan Kota yang Berkelanjutan. Malang: Group Konservasi Arsitektur \& Kota 